\title{
Effects of Chloramphenicol on the Mitochondrial Respiratory Chain in the Wild Strain and in a Cytoplasmic Chloramphenicol-Resistant Mutant of Tetrahymena pyriformis
}

\author{
ROLAND PERASSO,* JEAN-JACQUES CURGY, NICOLE STELLY, AND JEAN ANDRE \\ Laboratoire de Biologie Cellulaire 4, Université Paris-Sud, Centre Scientifique d'Orsay, 91405 Orsay, France
}

Received 3 August 1981/Accepted 3 February 1982

\begin{abstract}
The effects of chloramphenicol (CAP) on mitochondrial respiratory activity in the wild strain (ST) and in a cytoplasmic CAP-resistant mutant $\left(\mathrm{STR}_{1}\right)$ of Tetrahymena pyriformis were studied by determining oxygen consumption, by spectrophotometry, and by cytochemistry. In the absence of CAP both strains had the same respiration capacity, and the low-temperature spectra of their isolated mitochondria were similar. Furthermore, the mitochondria of both strains showed a positive reaction with diaminobenzidine, denoting a similar cytochrome oxidase activity. However, when cells were grown in CAP for 24 or $48 \mathrm{~h}$, the peaks of cytochrome oxidase and cytochrome $b$ were almost absent in the wild type. In this type the oxygen consumption was greatly decreased, and the mitochondria were no longer stained by diaminobenzidine. In the mutant, the peaks of cytochrome oxidase and cytochrome $b$ were decreased only; respiration was less affected than in the wild type, and cytochrome oxidase activity was still disclosed by the diaminobenzidine reaction. These results show that CAP inhibits the synthesis of two cytochromes ( $b$ and oxidase) which are partially translated into the mitochrondria of $T$. pyriformis. In the mutant, CAP reduces only the mitochondrial translation, resulting in reduced mitochondrial activity and reduced growth rate of the cell. These results are compared with the nucleo-mitochondrial regulation mechanisms discussed in our previous works.
\end{abstract}

The respiratory chain of Tetrahymena pyriformis ST is well known $(9,11,22)$. This chain differs from those of yeasts and higher organisms in many respects (see reference 9 for a review), one of which is the presence of abundant cytochrome $a_{2}$, which absorbs at $617 \mathrm{~nm}$. A cytoplasmic mutant $\left(\mathrm{STR}_{1}\right)$ resistant to chloramphenicol (CAP), a specific inhibitor of mitochondrial protein synthesis, has been isolated from strain ST of T. pyriformis (14). This mutant grows at the same rate as the wild strain in normal medium, but its growth is slowed in media supplemented with 250 or $500 \mu \mathrm{g}$ of CAP per ml (3). Cytoplasmic mutations conferring resistance to antibiotics induce modifications of the respiratory chain. These modifications have been clearly established in Paramecium tetraurelia (1). All of the cytoplasmic mutants observed, whether resistant to erythromycin or to CAP, have a longer generation time than that of the wild type and show a decreased amount of cytochrome oxidase, increased levels of cyanide-insensitive respiration, and a lowered $\mathrm{P} / \mathrm{O}$ ratio. These results are similar to those obtained with Neurospora $(6,10,21)$ and with a CAPresistant mutant of Podospora (2).

In T. pyriformis, the situation would seem to be different because both the mutant and wild types have the same generation time. Therefore, we compared the respiratory chain of both strains to disclose possible defects in the mutant.

The effect of CAP on growth and mitochondrial function in $T$. pyriformis was studied by Turner and Lloyd (22). These authors showed that growth of the cells is completely inhibited within a few generations by $500 \mu \mathrm{g}$ of CAP per $\mathrm{ml}$ and that after $72 \mathrm{~h}$ of CAP treatment the cells are respiratory deficient. More recently, in the ST strain of $T$. pyriformis grown in the presence of CAP, an important decrease in the mitochondrial contents of cytochrome $b$ and cytochrome oxidase was observed $(16,17)$. Therefore, the question may be raised whether CAP treatment of mutant cells (STR $)_{1}$ also causes modifications in the respiratory chain.

In the present work, the composition of the respiratory chain was studied by low-temperature spectrophotometry of reduced isolated mitochondria. The diaminobenzidine (DAB) reaction $(12,19)$ revealed the cytochrome oxidase activity of the mitochrondria in situ. Results are discussed on the basis of nucleo-mitochondrial regulation mechanisms in relation to our previ- 
ous works $(3,4,14 ;$ R. Perasso, Thèse d'Etat, Université de Paris-Sud, Orsay, France, 1980).

\section{MATERIALS AND METHODS}

Strains and culture conditions. Two strains were used for these experiments: the wild strain ST of $T$. pyriformis, and its cytoplasmic mutant $\mathrm{STR}_{1}$, which is resistant to CAP (14). Cells were grown as previously described (14).

Respiration of whole cells. The cells were concentrated by slow centrifugation $(800 \mathrm{rpm}$ for $3 \mathrm{~min}$ with a GGT centrifuge). A $0.2-\mathrm{ml}$ portion of the pellet was transferred to a chamber containing $1.5 \mathrm{ml}$ of $10^{-2} \mathrm{M}$ Tris-hydrochloride buffer (pH 7.2). Some experiments were performed without concentration of the cells. The inhibition tests were done with a solution of $1 \mathrm{M}$ $\mathrm{KCN}$ in $1 \mathrm{M}$ morpholinepropanesulfonic acid buffer (pH 7.4) and with a solution of $1 \mathrm{M}$ salicylhydroxamic acid in dimethyl formamide. $\mathrm{KCN}$ and salicylhydroxamic acid were added in the chamber to a final concentration of 1 to $2 \mathrm{mM}$. Oxygen uptake was measured polarographically with a Clarke oxygen electrode.

Evaluation of cell concentration. The evaluation of the number of cells per milliliter was done with a Coulter A Counter (Coultronics, Paris, France) on samples of 1 or $2 \mathrm{ml}$.

Isolation of mitochondria. Mitochondria were isolated by the procedure previously described (3).

Determination of protein contents. All protein determinations were carried out by the biuret method, with crystalline bovine serum albumin as a standard.

Spectrophotometry. The mitochondria were suspended in a medium containing $0.25 \mathrm{M}$ sucrose, $1 \mathrm{mM}$ EDTA, and $10 \mathrm{mM}$ Tris-hydrochloride (pH 7.4). The mitochondrial suspensions were adjusted to contain $100 \mathrm{mg}$ of protein per ml. Sodium hydrosulfite (dithionite) was used as the reducing agent. Low-temperature spectra were obtained with a Cary model 20 spectrophotometer.

Extraction of cytochrome c. A pellet of mitochondria was suspended in distilled water to obtain $2 \mathrm{mg}$ of protein per $\mathrm{ml}$. After homogenization with a Potter homogenizer, the mitochondria were allowed to stand for $5 \mathrm{~min}$ at $0^{\circ} \mathrm{C}$, and then crystallized $\mathrm{KCl}$ was added to obtain a final concentration of $0.25 \mathrm{M}$. After a second homogenization, the mitochondria were allowed to stand for $15 \mathrm{~min}$ at $0^{\circ} \mathrm{C}$. The suspension was centrifuged for $20 \mathrm{~min}$ at $30,000 \times g$. The supernatant contained cytochrome $c$. Another extraction of cytochrome $c$ with $\mathrm{KCl}$ was carried out by the same process on the pellet.

The two supernatants were pooled and dialyzed overnight at $4^{\circ} \mathrm{C}$ against distilled water. Centrifugation for $2 \mathrm{~h}$ at $100,000 \times g$ was then carried out to obtain a solution of cytochrome $c$ devoid of insoluble particles. The supernatant was lyophilized. The cytochrome $c$ was dissolved in phosphate buffer (10 mM, pH 7.3) and reduced with dithionite.

Cytochemistry and microscopy. Cytochemistry and microscopy were performed by the method of Stelly et al. (20).

\section{RESULTS}

Respiration of whole cells. (i) Cells grown without CAP (controls). Both strains were sensitive to $\mathrm{KCN}$. A complementary inhibition after the addition of salicylhydroxamic acid was never observed.

The oxygen uptake was similar for both strains grown in normal medium for 24 or $48 \mathrm{~h}$ (Fig. 1). The consumption of oxygen ranged from about 5.6 to $6.5 \mu \mathrm{M} \mathrm{O}_{2} \mathrm{~min}^{-1}$ per $10^{5}$ cells.

(ii) Cells grown with CAP. Modifications in the respiratory activity were observed in both strains (Fig. 1). In the wild strain, this activity decreased continuously as a function of the duration of CAP treatment. In the mutant strain, this activity decreased more slowly after $24 \mathrm{~h}$ of treatment. After $\mathbf{4 8}$ h, respiration increased but remained below that of the control.

Spectrophotometry. (i) Cells grown without CAP (controls). The absolute spectra of dithionite-reduced mitochondria from ST cells (Fig. 2) were similar to those obtained by several authors $(9,11,23)$. The extracted cytochrome $c$ of T. pyriformis absorbed at $551 \mathrm{~nm}$ (Fig. 2). Therefore, the peak at $553 \mathrm{~nm}$ probably corresponded to the composition of two absorbances: that of cytochrome $c_{551}$ and that of cytochrome $b_{556}$.

The low-temperature spectra of mitochondria of strain ST compared with those of strain STR showed no differences. Moreover, we did not observe any modification in these spectra related to the phase of the culture.

(ii) Cells grown with CAP. When cells were grown in CAP-containing medium for 24 or $48 \mathrm{~h}$, we observed important modifications in the spectra of the mitochondria from the wild type (Fig. 2). The peak $\alpha_{617} \mathrm{~nm}$ and the shoulder

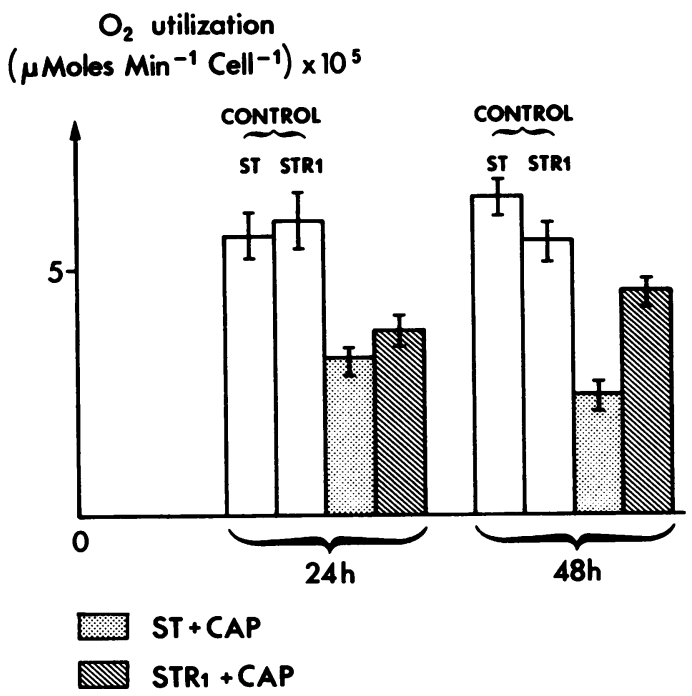

FIG. 1. $\mathrm{O}_{2}$ consumption of whole cells grown for 24 and $48 \mathrm{~h}$ in the absence (controls) or presence of CAP. ST and STR 1 are, respectively, the wild strain and the CAP-resistant mutant. 


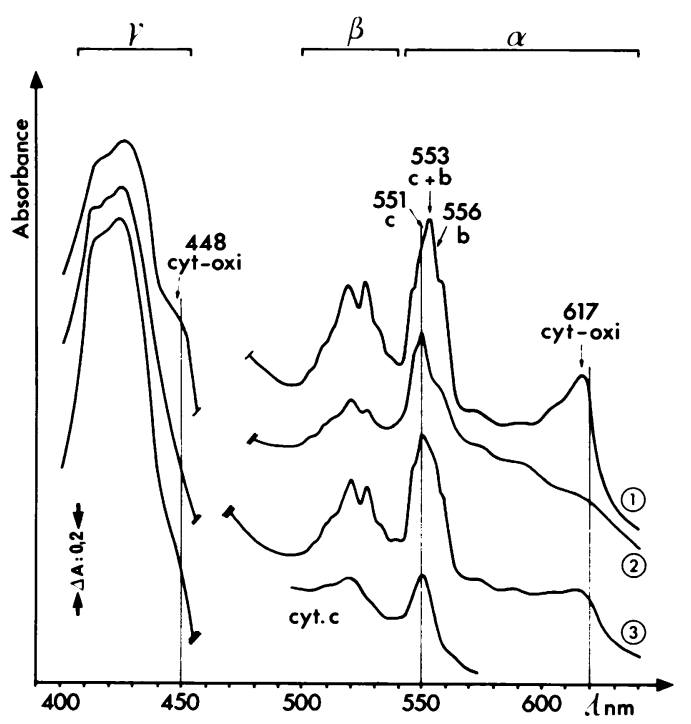

FIG. 2. Low-temperature spectra of reduced isolated mitochondria from cells grown for $48 \mathrm{~h}$ in CAPcontaining medium. Curve 1 , control spectrum of ST cells; curve 2, treated ST cells; curve 3, treated STR cells. Cytochrome oxidase (cyt-oxi) and cytochrome $b$ are very much affected in the ST strain. The effects of CAP are less pronounced in $\mathrm{STR}_{1}$ cells.

$\gamma_{448} \mathrm{~nm}$ of the cytochrome oxidase were almost absent. Moreover, cytochrome $b$ absorbance at $\alpha_{556 \mathrm{~nm}}$ and $\beta_{527 \mathrm{~nm}}$ was decreased.

CAP treatment for 24 or $48 \mathrm{~h}$ also led to modifications in the cytochrome spectra of the mutant, but these modifications were less pronounced than those observed in the wild type (Fig. 2). The decreased absorbance of cytochrome oxidase and cytochrome $b$ in the mutant persisted even after 7 days of treatment.

All spectrophotometry was carried out with samples containing the same concentration of mitochondrial protein. Thus, it was possible to estimate the relative loss of cytochrome oxidase in the wild type and in the mutant after CAP treatment. After $48 \mathrm{~h}$, this loss was about $80 \%$ for ST and only $30 \%$ for STR $_{1}$.

Cytochemistry. (i) Cells grown without CAP (controls). The mitochondria of both strains were stained with $D A B$ in the presence of $\mathrm{H}_{2} \mathrm{O}_{2}$ at $\mathrm{pH}$ 6. The results were similar to those of Hirai (7) and Stelly et al. (20) on strain ST of $T$. pyriformis. The stain was deposited along the cristae, but the deposits were not uniform (Fig. 3, a1 and b1). Staining also occurred on the mitochondrial envelope. DAB staining was eliminated by $\mathrm{KCN}$ (Fig. 3, a2 and b2).

(ii) Cells grown with CAP. After 24 or $48 \mathrm{~h}$ of CAP treatment, the mitochondria of the wild type showed severe alterations in their morphology (3) and a negative reaction in $\mathrm{DAB}-\mathrm{H}_{2} \mathrm{O}_{2}$ medium as well as in DAB- $\mathrm{H}_{2} \mathrm{O}_{2}-\mathrm{KCN}$ medium (Fig. 3, a3 and a4).

In the mutant, CAP treatment gave a different result. The mitochondria showed a positive reaction in DAB- $\mathrm{H}_{2} \mathrm{O}_{2}$ medium (Fig. 3, b3), but this reaction was less pronounced than that in the control (Fig. 3, b1). When KCN was added to the medium, all of the mitochondria were entirely DAB negative (Fig. 3, b4).

\section{DISCUSSION}

The oxigraphic traces of whole cells were similar for the wild strain and for the mutant and showed that respiration is eliminated by $\mathrm{KCN}$. Therefore, $T$. pyriformis does not have a branched respiratory chain with an alternative pathway insensitive to $\mathrm{KCN}$ and sensitive to salicylhydroxamic acid, as has been found in plants (18). Thus, $T$. pyriformis differs from the other ciliate $P$. tetraurelia, which possesses such a branched respiratory chain (5).

The mitochondria of both strains had the same respiratory activity and cytochrome contents: the low-temperature spectra of reduced mitochondria were similar, and the DAB reaction, which under our conditions localizes a cytochrome oxidase activity $(8,19,20)$, was positive in both kinds of mitochondria. When the cells were grown in CAP-containing medium, the mitochondria of the wild strain had a respiratory activity which decreased progressively during the treatment. Their low-temperature spectra showed that cytochrome oxidase and cytochrome $b$ were present in low quantities. In the mutant, the quantity of these two cytochromes was only slightly decreased after 24 and $48 \mathrm{~h}$ of CAP treatment. In the same way, the respiratory activity decreased after $24 \mathrm{~h}$ of treatment, but did not remain constant; it increased slightly after $48 \mathrm{~h}$. The cytochemical study with DAB corroborated these results. In the wild strain, we did not detect any positive reaction. This suggests that there is very little cytochrome oxidase in the mitochondria, undetectable by the DAB reaction. In contrast, in the mutant, the deposits observed on the inner mitochondrial membrane showed that cytochrome oxidase activity persisted after CAP treatment.

Mutant and wild types of $T$. pyriformis have the same generation time (3) and the same capacity of respiration, and their mitochondria show the same cytochrome spectrum. Our CAP. resistant mutant differed from a series of mitochondrial mutants: the poky mutant of Neurospora, which displays a lowered amount of cytochromes $a-a_{3}$ and $b$ and a decreased growth rate (10); a CAP-resistant mutant of Podospora deficient in cytochrome $a-a_{3}$ (2); and a CAP- 

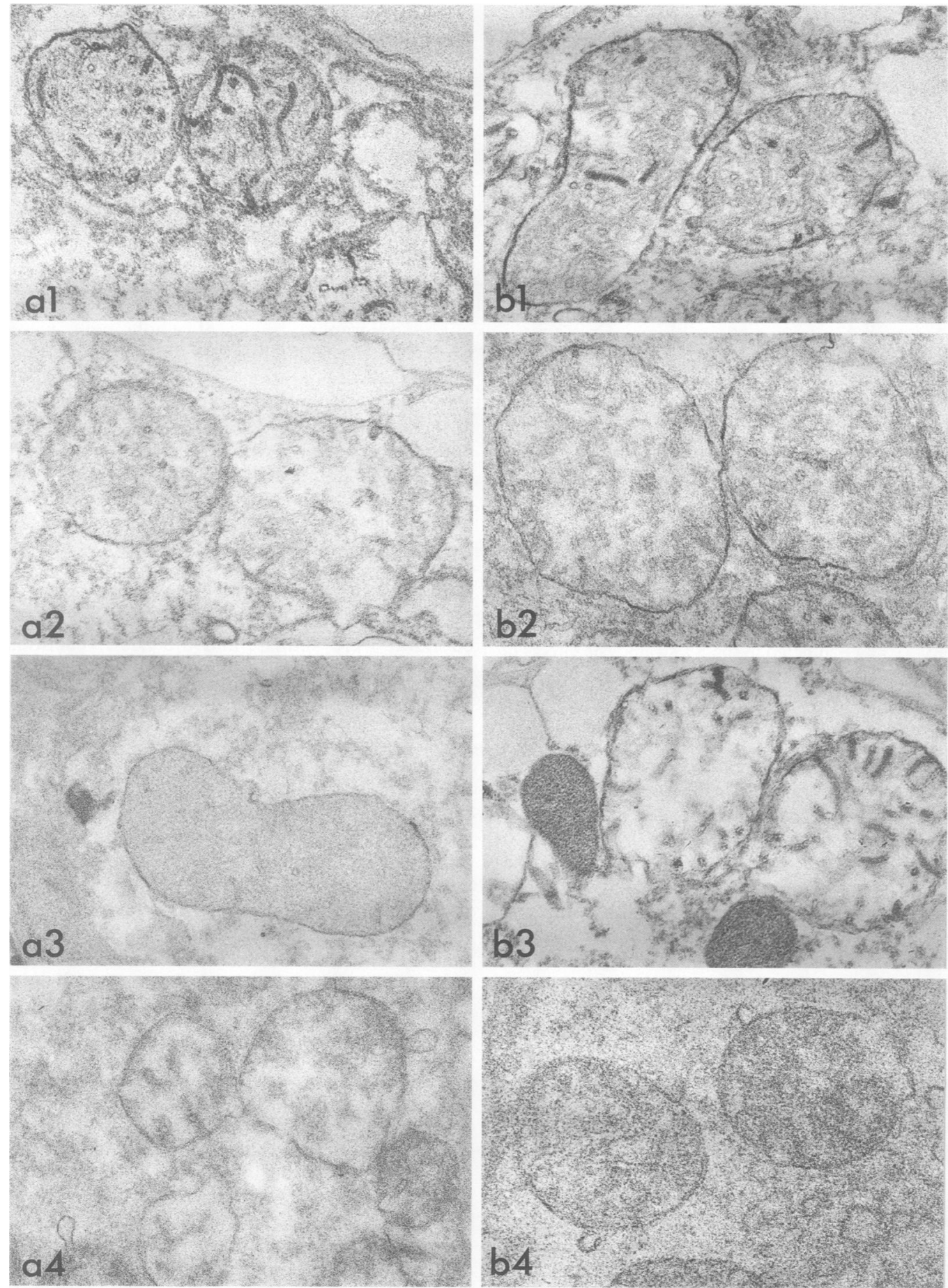

FIG. 3. DAB reactivity in the mitochondria of strain $S T$ (a) and strain $S_{T} R_{1}$ (b). (a1 and b1) Mitochondrial staining in DAB- $\mathrm{H}_{2} \mathrm{O}_{2}$ medium; both kinds of mitochondria are stained. (a2 and b2) Controls in $\mathrm{DAB}-\mathrm{H}_{2} \mathrm{O}_{2}-$ $\mathrm{KCN}$ medium; full inhibition of staining has occurred. (a3, a4, b3, and b4) DAB reactivity in mitochondria of CAP-treated $T$. pyriformis (CAP treatment, $250 \mu \mathrm{g} / \mathrm{ml}$ for $48 \mathrm{~h}$ ). (a3 and b3) Mitochondrial staining in DAB- $\mathrm{H}_{2} \mathrm{O}_{2}$ medium; only the mitochondria of STR 1 are stained. (a4 and b4) Controls in DAB- $\mathrm{H}_{2} \mathrm{O}_{2}-\mathrm{KCN}$ medium; full inhibition of staining has occurred. $(\times 30,000)$ 
resistant mutant of $T$. pyriformis, isolated by Roberts and Orias (15), which shows a reduced growth rate and cytoplasmic inheritance.

In a previous study, we showed that in the mutant grown for $24 \mathrm{~h}$ in CAP-containing medium, the mitochondria display the same morphological alterations as those of the wild type, but recover an almost normal morphology after $48 \mathrm{~h}$ of CAP treatment (3). The data shown in Fig. 1 relating to the oxygen uptake by the mitochondria of the mutant grown under the same conditions are in agreement with this point. After $24 \mathrm{~h}$ of treatment, when their morphology was greatly altered, the mitochondria had a low capacity of respiration (63\% of the control), whereas after $48 \mathrm{~h}$ they had recovered a morphology and respiratory activity which were almost normal ( $82 \%$ of the control).

The resistance to CAP of the $\mathrm{STR}_{1}$ mutant is due to a modification in the protein contents of the mitoribosomes (4). These mitoribosomes bound less to CAP than those of the wild strain did (4). We can explain the mitochondrial behavior of the mutant in terms of nucleo-mitochondrial regulatory mechanisms, with the following hypothesis. In the first step, the antibiotic causes a lack of balance between the decreased translation in the mitochondria and the unchanged translation in the cytoplasmic background. Then, a new balance between the activity of the two translational systems is established, due to an increase in the number of mitoribosomes (4) and to a decrease in the growth rate of the cell which is, in turn, controlled by the rate of ATP production by the mitochondria $(5,13)$.

\section{ACKNOWLEDGMENTS}

We are indebted to $P$. Slonimski and $P$. Pajot (Centre de Génétique Moléculaire, CNRS, Gif-sur-Yvette, France) for kindly allowing our use of the Cary 20 spectrophotometer, and to G. Dubertret (Laboratoire de Cytophysiologie de la Photosynthèse, CNRS) for his help in the respiratory studies. We thank E. Boissonneau, A. Charrier, C. Couanon, and F. Iftode for expert technical assistance.

This work was partially supported by the Centre National de la Recherche Scientifique (E.R.A. 174), and by the Fondation pour la Recherche Médicale Française.

\section{LITERATURE CITED}

1. Adoutte, A., and J. Doussière. 1978. Physiological consequences of mitochondrial antibiotic-resistant mutations in Paramecium. Mol. Gen. Genet. 161:121-134.

2. Belcour, L., and O. Begel. 1977. Mitochondrial genes in Podospora anserina: recombination and linkage. Mol. Gen. Genet. 153:11-21.

3. Curgy, J. J., F. Iftode, R. Perasso, and J. André. 1980. Croissance des cultures et morphologie des mitochondries chez des mutants à hérédité cytoplasmique, résistants au chloramphénicol, de Tetrahymena pyriformis. Biol. Cell. 37:51-60.

4. Curgy, J. J., R. Perasso, E. Boissonneau, F. Iftode, N. Stelly, and J. Andre. 1981. The mitoribosomes of a chlor- amphenicol-resistant cytoplasmic mutant of Tetrahymena pyriformis differ from those of the wild strain. Curr. Genet. 4:121-130.

5. Doussière, J., A. Adoutte, A. Sainsard, F. Ruiz, J. Beisson, and P. Vignais. 1976. Physiological and genetical analysis of the respiratory chain of Paramecium, p. 873-880. In T. Bücher, W. Neupert, W. Sebald, and S. Werner (ed.), Genetics and biogenesis of chloroplasts and mitochondria. Elsevier/North-Holland Publishing Co., Amsterdam.

6. Haskins, F. A., A. Tissières, H. K. Mitchell, and M. B. Mitchell. 1953. Cytochromes and the succinic acid-oxidase system of poky strains of Neurospora. J. Biol. Chem. 200:819-826.

7. Hirai, K. I. 1971. Comparison between 3,3'-diaminobenzidine and auto-oxidized 3,3'-diaminobenzidine in the cytochemical demonstration of oxidative enzymes. J. Histochem. Cytochem. 19:434-442.

8. Keyhani, E. 1972. Localisation cytochimique de la cytochrome-oxydase chez la levure Candida utilis. J. Microsc. (Paris) 15:343-352.

9. Kilpatrick, L., and M. Erecinska. 1977. Mitochondrial respiratory chain of Tetrahymena pyriformis: the thermodynamic and spectral properties. Biochim. Biophys. Acta 460:346-363.

10. Lambowitz, A. M., E. W. Smith, and C. W. Slayman. 1972. Electron transport in Neurospora mitochondria: studies on wild-type and poky. J. Biol. Chem. 247:4850 4858.

11. Lloyd, D., and B. Chance. 1972. The cytochromes of mitochondria from Tetrahymena pyriformis strain ST. Biochem. J. 128:1171-1182.

12. Novikof, A. B., and S. Goldfischer. 1969. Visualization of peroxisomes (microbodies) and mitochondria with diaminobenzidine. J. Histochem. Cytochem. 17:675-680.

13. Perasso, R., and J. Beisson. 1978. Temporal pattern of mitochondrial multiplication during the cell cycle of Paramecium. Biol. Cell. 32:275-290.

14. Perasso, R., J. J. Curgy, F. Iftode, and J. André. 1980. Isolement de mutants à hérédité cytoplasmique, résistants au chloramphénicol, chez Tetrahymena pyriformis. Biol. Cell. 37:45-49.

15. Roberts, C. T., and E. Orias. 1973. Cytoplasmic inheritance of chloramphenicol resistance in Tetrahymena. Genetics 73:259-272.

16. Rohatgi, K., and S. Krawiec. 1973. Some effects of chloramphenicol and ethidium bromide on Tetrahymena pyriformis. J. Protozool. 20:425-430.

17. Ruben, L., and A. B. Hooper. 1978. Chloramphenicolinduced growth arrest in animal cells: presence of nonadenylate-mediated feedback control in Tetrahymena. J. Biol. Chem. 253:7262-7268.

18. Schonbaum, G. S., W. D. Bonner, Jr., B. T. Storey, and J. T. Bahr. 1971. Specific inhibition of the cyanideinsensitive respiratory pathway in plant mitochondria by hydroxamic acids. Plant Physiol. (Bethesda) 47:124-128.

19. Seligman, A., M. J. Karnovsky, H. L. Wasserkrug, and J. S. Hanker. 1968. Nondroplet ultrastructural demonstration of cytochrome oxidase with a polymerizing osmiophilic reagent, diaminobenzidine (DAB). J. Cell Biol. 38:1-14.

20. Stelly, N., M. Balmefrézol, and A. Adoutte. 1975. Diaminobenzidine reactivity of mitochondria and peroxisomes in Tetrahymena and in wild-type and cytochrome oxidasedeficient Paramecium. J. Histochem. Cytochem. 23:686696.

21. Tissières, A., H. K. Mitchell, and F. A. Haskins. 1953. Studies on the respiratory system of the poky strain of Neurospora. J. Biol. Chem. 205:423-433.

22. Turner, G., and D. Lloyd. 1971. The effect of chloramphenicol on growth and mitochondrial function of the ciliate protozoan Tetrahymena pyriformis strain ST. J. Gen. Microbiol. 67:175-188.

23. Turner, G., D. Lloyd, and B. Chance. 1971. Electron transport in phosphorylating mitochondria from Tetrahymena pyriformis strain ST. J. Gen. Microbiol. 65:359-374. 